Mens

Revue d'histoire intellectuelle et culturelle

\title{
Note de gérance
}

\section{Jean-François Laniel}

Volume 19, numéro 1-2, automne 2018, printemps 2019

URI : https://id.erudit.org/iderudit/1070065ar

DOI : https://doi.org/10.7202/1070065ar

Aller au sommaire du numéro

\section{Éditeur(s)}

Centre de recherche en civilisation canadienne-française

\section{ISSN}

1492-8647 (imprimé)

1927-9299 (numérique)

Découvrir la revue

Citer ce document

Laniel, J.-F. (2018). Note de gérance. Mens, 19(1-2), 5-7.

https://doi.org/10.7202/1070065ar d'utilisation que vous pouvez consulter en ligne.

https://apropos.erudit.org/fr/usagers/politique-dutilisation/ 


\section{Note de gérance}

La «nouvelle sensibilité historique» fêtait en 2018 le quinzième anniversaire de son ouvrage manifeste Les idées mènent le Québec: essais sur une sensibilité historique. Elle y affirmait son projet de "comprendre le présent en examinant les utopies et les idéaux qui animaient les générations précédentes». Afin de «réexamin[er] les "principes premiers" qui ont inspiré notre aventure collective», elle se devait de déployer un "effort de réinterprétation systématique du passé récent» où "l'influence des idées, de la politique et de la religion [serait] sérieusement réaffirmée ${ }^{1}$ ». En creux, on proposait une réinterprétation compréhensive du passé canadien-français, trop souvent réduit au rôle de faire-valoir obscur d'une modernité lumineuse. Il s'agissait donc de «restaurer le passé comme espace de signification qui parle au présent" afin de "rétablir les chầnons manquants d'une dialectique défectueuse ${ }^{2}$ " entre la tradition et la modernité. Dans le même «esprit " était fondée quelques années plus tôt la revue Mens, consacrée à une histoire intellectuelle récusant

cette attitude qui consiste à traîner ses devanciers au banc des accusés du tribunal de l'Histoire, car nous croyons que l'objectif de tout travail historique sérieux, honnête et utile devrait être de rendre compte du passé dans toute sa richesse, sa complexité et sa subtilité, avec ses grandeurs et ses misères, ses coups de génie

1 Stéphane Kelly, «Introduction», dans Stéphane Kelly (dir.), Les idées mènent le Québec: essais sur une sensibilité historique, Québec, Presses de l'Université Laval, 2003, p. 4.

2 Lucille Beaudry et Marc Chevrier, «Pensée critique, conservatisme ou libéralisme?: considérations sur l'horizon politique et philosophique de la "nouvelle sensibilité" ", dans Lucille Beaudry et Marc Chevrier (dir.), Une pensée libérale, critique ou conservatrice?: actualité de Hannah Arendt, d'Emmanuel Mounier et de Georges Grant pour le Québec d'aujourd'hui, Québec, Presses de l'Université Laval, p. 21 et 24. 
et ses contradictions. Bref, le travail de l'historien consiste avant tout à comprendre le passé, non à le juger ${ }^{3}$.

Un premier bilan de cette tentative de relecture compréhensive du passé québécois devra un jour être fait, jour que nous espérons proche. Notons, à cette fin, que les différents numéros de Mens, publiés au fil des vingt dernières années, figureront certainement aux premières loges de ce travail collectif de reconsidération de notre passé plus ou moins récent. Notons surtout, pour l'heure, à quel point le présent numéro, «Les années 1840: rupture ou réarticulation des possibles?", nous semble exemplaire de la démarche propre à la «nouvelle sensibilité historique», en même temps que de sa fécondité toujours renouvelée. Il plonge, d'une part, au cour de la (re)fondation du peuple français d'Amérique à la suite de l'échec des rébellions patriotes, alors que voit le jour un nouveau (ou un premier) nationalisme proprement canadien-français, que Fernand Dumont considérera plus tard comme le fondement de "la genèse de la société québécoise». Il offre un regard nuancé sur les débuts de cette "grande noirceur" qui aurait duré plus d'un siècle, à propos de laquelle les directrices du dossier se demandent si on peut y voir autre chose qu'un «moment de repli culturel». Les collaboratrices et collaborateurs de la revue se penchent également sur cette question en soulignant moins le traditionalisme réactionnaire des personnalités publiques d'alors que leur romantisme libéral ou conservateur, moins l'amodernité du Canada français que sa participation singulière aux idéaux et aux processus de la modernité, notamment par le biais de l'instruction publique et de la circulation continentale des textes et des réflexions d'ici, auxquels contribuèrent de nombreuses femmes en prenant la plume ou en formant les nouvelles générations, par exemple.

3 Maude Beausoleil et al., "Présentation", Mens: revue d'histoire intellectuelle de l'Amérique française, vol. I, no 1 (automne 2000), p. 3-6, [En ligne], [http:// www.revuemens.ca/?page_id=204] (3 janvier 2020). 
Entre tradition et modernité, entre continuité et rupture, entre lumière et noirceur, ce numéro de Mens nous aide à comprendre l'esprit complexe et subtil d'une époque. On ne saurait demander mieux.

Jean-François Laniel

Pour l'équipe de Mens 